\title{
Compactação do solo no desenvolvimento radicular e na produtividade da soja
}

\author{
Amauri Nelson Beulter ${ }^{(1)}$ e José Frederico Centurion ${ }^{(1)}$
}

(1)Universidade Estadual Paulista, Fac. de Ciências Agrárias e Veterinárias, Dep. de Solos e Adubos, Via de Acesso Prof. Paulo Donato Castellane, s/noำ, CEP 14870-000 Jaboticabal, SP. E-mail: amaurib@yahoo.com.br, jfcentur@fcav.unesp.br

Resumo - Em solos compactados ocorrem mudanças na distribuição do sistema radicular das plantas em profundidade. $\mathrm{O}$ objetivo deste trabalho foi avaliar o efeito da compactação do solo no desenvolvimento radicular e na produtividade da soja em Latossolo Vermelho de textura média. Os tratamentos constituíram-se de 0, 1, 2, 4 e 6 passadas de um trator, lado a lado, sobre a superfície do solo. O delineamento experimental usado foi o inteiramente casualizado, com quatro repetições. Em dezembro de 2002, foi semeada soja (Glycine max cv. Embrapa 48) e, após a semeadura, foram coletadas amostras de solo nas camadas de $0,02-0,05,0,07-0,10$ e $0,15-0,18 \mathrm{~m}$, para determinações físicas. No estádio R6 foram coletadas amostras de $0,10 \mathrm{~m}$ no sentido da linha x $0,20 \mathrm{~m}$ no sentido da entrelinha, nas camadas de $0,0-0,05,0,05-0,10,0,10-0,15$ e $0,15-0,20 \mathrm{~m}$, e na maturação das plantas foi avaliada a produtividade de grãos de soja em parcelas de $3,6 \mathrm{~m}^{2}$. O aumento da compactação elevou a densidade radicular e a massa de matéria seca das raízes, na camada de 0,0-0,05 m, e causou decréscimo linear nas camadas mais compactadas de $0,05-0,10$ e $0,10-0,15$ m. A partir do decréscimo de $18 \%$ da densidade radicular, na resistência do solo à penetração de $0,85 \mathrm{MPa}$, na camada de $0,05-0,15 \mathrm{~m}$, ocorreu redução na produtividade de grãos da soja. A compactação do solo promoveu modificações na distribuição do sistema radicular de soja.

Termos para indexação: densidade do solo, resistência à penetração, impedimento ao crescimento, raízes, soja.

\section{Effect of soil compaction in root development and in soybean yield}

Abstract - In compacted soils, changes in the distribution of plant root system occur in depth. The objective of this study was to evaluate the compaction effect in soybean root development and yield in an Oxisol. The treatments were $0,1,2,4$ and 6 passed of a $11 \mathrm{Mg}$ tractor, side, by side, on soil surface. The experimental design was a completely randomized, with four replications. In December, 2002, soybean (Glycine max cv. Embrapa 48) was sown, and after that, the samples were collected in layers of $0.02-0.05,0.07-0.10$ and $0.15-0.18 \mathrm{~m}$, for physical determinations. In R6 stadium, samples of $0.10 \mathrm{~m}$ in line $\mathrm{x} 0.20 \mathrm{~m}$ between lines, in layers of $0.0-0.05$, $0.05-0.10,0.10-0.15$ and $0.15-0.20 \mathrm{~m}$ were collected. Soybean yield was evaluated in plots of $3.6 \mathrm{~m}^{2}$. The increase in compaction increased the root density and the root dry matter in layer of $0.0-0.05 \mathrm{~m}$ and caused linear decrease in the most compacted layers of $0.05-0.10$ and $0.10-0.15 \mathrm{~m}$. From the decrease of $18 \%$ of root density, in resistance to penetration of $0.85 \mathrm{MPa}$, in the depth of $0.05-0.15 \mathrm{~m}$, there was reduction in soybean yield. Soil compaction promoted modifications in the distribution of the soybean root system.

Index terms: bulk density, resistance to penetration, growth impediment, roots, soybean.

\section{Introdução}

A soja tem sido amplamente cultivada no Brasil por sua importância alimentar e econômica, sendo crescente a utilização do sistema de plantio direto (SPD) (Agrianual, 2001). Entretanto, o tráfego de máquinas pesadas no SPD tem provocado compactação superficial do solo (Silva et al., 2000b) e reduzido a produtividade das culturas (Beutler \& Centurion, 2003).
Em solos compactados ocorre alteração da estrutura e, conseqüentemente, decréscimo da porosidade, da macroporosidade, da disponibilidade de água e nutrientes e da difusão de gases no solo (Taylor \& Brar, 1991), cujas relações com o desenvolvimento das raízes são fundamentais. Segundo Queiroz-Voltan et al. (2000), em solos compactados, as raízes das plantas não utilizam adequadamente os nutrientes disponíveis, uma vez que o desenvolvimento de novas raízes, responsáveis pela 
absorção de água e nutrientes, fica prejudicado. Além disso, esses autores mencionam que a quantidade de oxigênio na rizosfera pode ser limitante nos processos metabólicos. Segundo Hakansson et al. (1998), em solos compactados, o menor desenvolvimento do sistema radicular resulta em menor volume de solo explorado pelas raízes e, conseqüentemente, menor absorção de água e nutrientes.

Tanto em casa de vegetação (Rosolem et al., 1994 Queiroz-Voltan et al., 2000; Guimarães et al., 2002) como no campo (Merten \& Mielniczuk, 1991; Silva et al., 2000a), as raízes apresentam dificuldades em penetra nas camadas compactadas, promovendo maior desenvolvimento radicular na camada superior ou inferior menos compactada, como forma de compensar a redução do desenvolvimento radicular na camada de solo compactada.

Segundo Pabin et al. (1998), a redução de 40\% no comprimento radicular é crítica à produtividade das plantas em solo arenoso. Cintra \& Mielniczuk (1983) verificaram uma redução de 50\% no comprimento radicular de várias culturas na resistência do solo à penetração (RP) de 1,10 MPa, em Latossolo Roxo. Mielniczuk et al (1985) constataram uma redução de $86 \%$ no comprimento radicular da soja, em vasos, quando a RP foi de 2,35 MPa, porém, não decrescendo a massa de matéria seca da parte aérea, em um Latossolo Roxo. Rosolem et al. (1994), em vasos, verificaram que na RP de 0,69 $\mathrm{MPa}$ houve uma redução de $50 \%$ no comprimento radicular da soja, em Latossolo Vermelho-Escuro. Em geral, tem-se adotado o valor de RP de 2,0 MPa como crítico ao crescimento radicular (Tormena et al. 1998).

O objetivo deste trabalho foi avaliar o efeito da compactação do solo no desenvolvimento radicular e na produtividade da soja em Latossolo Vermelho de textura média.

\section{Material e Métodos}

O experimento foi realizado na Universidade Estadual Paulista, Faculdade de Ciências Agrárias e Veterinárias, Jaboticabal, SP (21ํ 15' 29" S, 48 16' 53" W; 607 m de altitude). O clima é do tipo Cwa, ou seja, temperaturas moderadas no verão quente e chuvoso, segundo o sistema de classificação de Köppen (Brasil, 1960).

O solo foi classificado como Latossolo Vermelho distrófico, típico, textura média, horizonte A moderado, caulinítico hipoférrico (LVd), cuja composição granulométrica na camada de 0,0-0,20 $\mathrm{m}$ (argila, $271 \mathrm{~g} \mathrm{~kg}^{-1}$; silte, $42 \mathrm{~g} \mathrm{~kg}^{-1} \mathrm{e}$ areia $687 \mathrm{~g} \mathrm{~kg}^{-1}$ ) foi determinada por meio da dispersão com $\mathrm{NaOH} 0,1 \mathrm{~mol} \mathrm{~L}^{-1} \mathrm{e}$ agitação lenta durante 16 horas, e o conteúdo de argila, obtido pelo método da pipeta (Gee \& Bauder, 1986).

Antes da instalação do experimento, foi realizada escarificação do solo até $0,30 \mathrm{~m}$ de profundidade, seguida de uma gradagem. Os tratamentos constituíramse de $0,1,2,4$ e 6 passadas de um trator de $11 \mathrm{Mg}$, com quatro pneus de mesma largura $(0,40 \mathrm{~m})$ e pressão interna, uma ao lado da outra, no sentido do declive da área, perfazendo toda a superfície, quando o conteúdo de água no solo estava próximo da capacidade de campo $(0,01 \mathrm{MPa})$.

O delineamento experimental foi inteiramente casualizado, com cinco níveis de compactação, quatro repetições e parcelas de $9,0 \mathrm{~m}^{2}$.

A caracterização química do solo foi realizada segundo Raij et al. (1987), e a adubação na semeadura foi de $50 \mathrm{~kg} \mathrm{ha}^{-1}$ de sulfato de amônio, $125 \mathrm{~kg} \mathrm{ha}^{-1}$ de superfosfato triplo e $85 \mathrm{~kg} \mathrm{ha}^{-1}$ de cloreto de potássio, para obtenção da produtividade esperada de soja de 3,0 $\mathrm{Mg} \mathrm{ha}^{-1}$, segundo Raij et al. (1996).

Em 10 de dezembro de 2002, as sementes de soja (Glycine max cv. Embrapa 48) receberam inóculos de Bradyrhizobium japonicum e foram semeadas na profundidade de 0,05 m e espaçamento de 0,45 m entre linhas, no sentido transversal ao declive da área, e o desbaste foi realizado 10 dias após a semeadura, deixando 20 plantas por $m$ linear.

Após a semeadura, foram coletadas amostras de solo com cilindros de $53,16 \times 10^{-6} \mathrm{~m}^{3}$ nas camadas de $0,02-0,05,0,07-0,10$ e $0,15-0,18 \mathrm{~m}$, as quais foram saturadas e submetidas à tensão de 0,006 MPa em câmaras de Richards (Klute, 1986) e pesadas ao atingirem o equilíbrio. Em seguida, foram submetidas à tensão de 0,01 MPa, e quando atingiram o equilíbrio foi determinada a resistência do solo à penetração (RP), com duas determinações por amostra, com o penetrômetro eletrônico em velocidade constante de penetração de $0,01 \mathrm{~m} \mathrm{~min}^{-1}$, e cone com área de $3,14 \times 10^{-6} \mathrm{~m}^{2}$, conforme Tormena et al. (1998). Em seguida, as amostras foram secadas em estufa a $105^{\circ} \mathrm{C}$ durante 24 horas e pesadas para determinação da densidade (Blake \& Hartge, 1986), da porosidade total segundo Danielson $\&$ Sutherland (1986), da microporosidade na tensão de $0,006 \mathrm{MPa}$ (Klute, 1986) e da macroporosidade por diferença entre a porosidade total e a microporosidade. 
No estádio R6 da soja (enchimento de grãos), na escala de Fehr et al. (1971), foram coletadas amostras de solo de $0,10 \mathrm{~m}$ no sentido da linha $\mathrm{x} 0,20 \mathrm{~m}$ no sentido da entrelinha, com caixas de metal, a partir da raiz principal das plantas, nas camadas de $0,0-0,05,0,05-0,10$, 0,10-0,15 e 0,15-0,20 m. Em seguida, as raízes foram separadas do solo por lavagem em água corrente, utilizando peneira de $0,005 \mathrm{~m}$. As imagens das raízes foram digitalizadas em um "scanner" de leitura ótica, na resolução de $200 \mathrm{dpi}$, e analisadas quanto à densidade, superfície e diâmetro radicular pelo programa "Win Msc Rhyzo", versão 3.8. Na seqüência, as amostras foram secadas a $65^{\circ} \mathrm{C}$, para determinação da massa de matéria seca. Após a maturação da soja, foi determinada a produtividade de grãos a partir da parcela útil de $3,6 \mathrm{~m}^{2}$.

Os resultados obtidos foram submetidos à análise de variância e análise de regressão entre a resistência do solo à penetração e os componentes de desenvolvimento radicular e a produtividade de grãos de soja.

\section{Resultados e Discussão}

Ocorreu uma camada mais compactada na profundidade de $0,07-0,10 \mathrm{~m}$, e com menor compactação na profundidade de 0,15-0,18 m (Tabela 1). Silva et al. (2000b), em sistema de plantio direto, também verificaram a formação de uma camada de solo mais compactada na camada de $0,05-0,15$ m por causa do tráfego de colhedora sobre o solo.

Tabela 1. Valores médios dos atributos físicos do Latossolo Vermelho nas diferentes camadas e passadas de trator.

\begin{tabular}{cccccc}
\hline $\begin{array}{c}\text { Camada } \\
(\mathrm{m})\end{array}$ & \multicolumn{5}{c}{ Passadas de trator } \\
\cline { 2 - 6 } $0,02-0,05$ & 0 & 2 & 4 & 6 \\
$0,07-0,10$ & 0,28 & 0,10 & 0,06 & 0,05 & 0,03 \\
$0,15-0,18$ & 0,24 & 0,06 & 0,05 & 0,04 & 0,04 \\
\hline \multicolumn{5}{c}{ Microporosidade $\left(\mathrm{m}^{3} \mathrm{~m}^{-3}\right)$} & 0,05 \\
$0,02-0,05$ & 0,18 & 0,08 & 0,06 & 0,05 \\
$0,07-0,10$ & 0,24 & 0,29 & 0,30 & 0,29 & 0,29 \\
$0,15-0,18$ & 0,25 & 0,29 & 0,28 & 0,28 & 0,28 \\
\hline \multicolumn{7}{c}{ Resistência à penetração (MPa) $)^{(1)}$} \\
$0,02-0,05$ & 0,28 & 0,30 & 0,30 & 0,29 & 0,28 \\
$0,07-0,10$ & 0,21 & 1,00 & 1,92 & 3,58 & 4,57 \\
$0,15-0,18$ & 0,32 & 2,38 & 2,63 & 4,40 & 4,10 \\
\hline \multicolumn{7}{c}{ Densidade do solo (Mg m-3 } \\
$0,02-0,05$ & 0,65 & 2,07 & 3,65 & 3,04 \\
$0,07-0,10$ & 1,19 & 1,54 & 1,70 & 1,74 & 1,80 \\
$0,15-0,18$ & 1,31 & 1,68 & 1,76 & 1,82 & 1,81 \\
& 1,46 & 1,64 & 1,74 & 1,77 & 1,78 \\
\hline
\end{tabular}

Determinaco mealizada na umidade correspondente à capacid campo $(0,01 \mathrm{MPa})$.
Por ser a RP o atributo físico do solo atualmente mais utilizado como indicativo da compactação do solo, foram estabelecidas equações de regressão da RP com os componentes de desenvolvimento radicular (Figura 1). No tratamento com solo revolvido e não trafegado $(0,39 \mathrm{MPa})$, ocorreu melhor distribuição do sistema radicular em profundidade e uma maior concentração de raízes até $0,10 \mathrm{~m}$ de profundidade em relação aos tratamentos nos quais o solo foi compactado com o trator e que apresentou maior quantidade de raízes até $0,05 \mathrm{~m}$, verificado por meio da densidade, superfície e massa de matéria seca das raízes. Nesse tratamento, obteve-se, na camada de $0,00-0,10 \mathrm{~m}, 73 \%$ da massa de matéria seca total até a profundidade $0,20 \mathrm{~m}$, corroborando os resultados de Merten \& Mielniczuk (1991), que verificaram, na camada de $0,0-0,10 \mathrm{~m}$, que a massa de matéria seca de raízes de soja foi de $80 \%$ do total até a profundidade de $0,40 \mathrm{~m}$, em sistema de plantio convencional e direto em Latossolo Roxo, os quais não diferiram estatisticamente entre si. A melhor distribuição do sistema radicular na condição de solo solto está relacionada a maior porosidade e menor impedimento mecânico ao desenvolvimento radicular.

O aumento do número de passagens de máquina sobre o solo proporcionou um aumento linear da densidade de raízes e quadrático da superfície radicular na camada de 0,0-0,05 m e decréscimo linear na camada de 0,05-0,15 m, com menores alterações na camada de 0,15-0,20 m (Figura 1). Estes resultados são explicados pelo maior valor de RP na camada de 0,05-0,10 m, dificultando a penetração das raízes nessa camada. Segundo Borges et al. (1988), as raízes das plantas de soja se desenvolvem melhor em pontos de menor RP, razão pela qual ocorrem modificações na morfologia da raiz, como a redução no comprimento radicular quando estas encontram impedimento mecânico. Benghough \& Mullins (1990) afirmam que o menor crescimento radicular em solos compactados ocorre por causa da menor taxa de elongação celular em razão da diminuição na taxa de divisão celular do meristema.

Houve maior densidade e superfície radicular na camada de 0,0-0,05 m, com o aumento da RP na camada de 0,05-0,15 m, corroborando Silva et al. (2000a), que verificaram maior densidade radicular de milho na camada de 0,0-0,05 m no plantio direto quando comparado ao sistema convencional, em Podzólico Vermelho-Amarelo. $\mathrm{O}$ aumento na densidade radicular na camada de 0,0-0,05 m está associado ao menor cresci- 
mento radicular na camada compactada, como também verificado por Rosolem et al. (1994). Segundo Camargo \& Alleoni (1997), o aumento da compactação e conseqüente redução do tamanho dos poros, a ponto de impedir a passagem da raiz principal, leva a compensar esse efeito pela expansão de raízes laterais com diâmetros menores, que se proliferam e formam um sistema radicular muito denso e raso, que no campo dificilmente sobrevive a condições de seca.
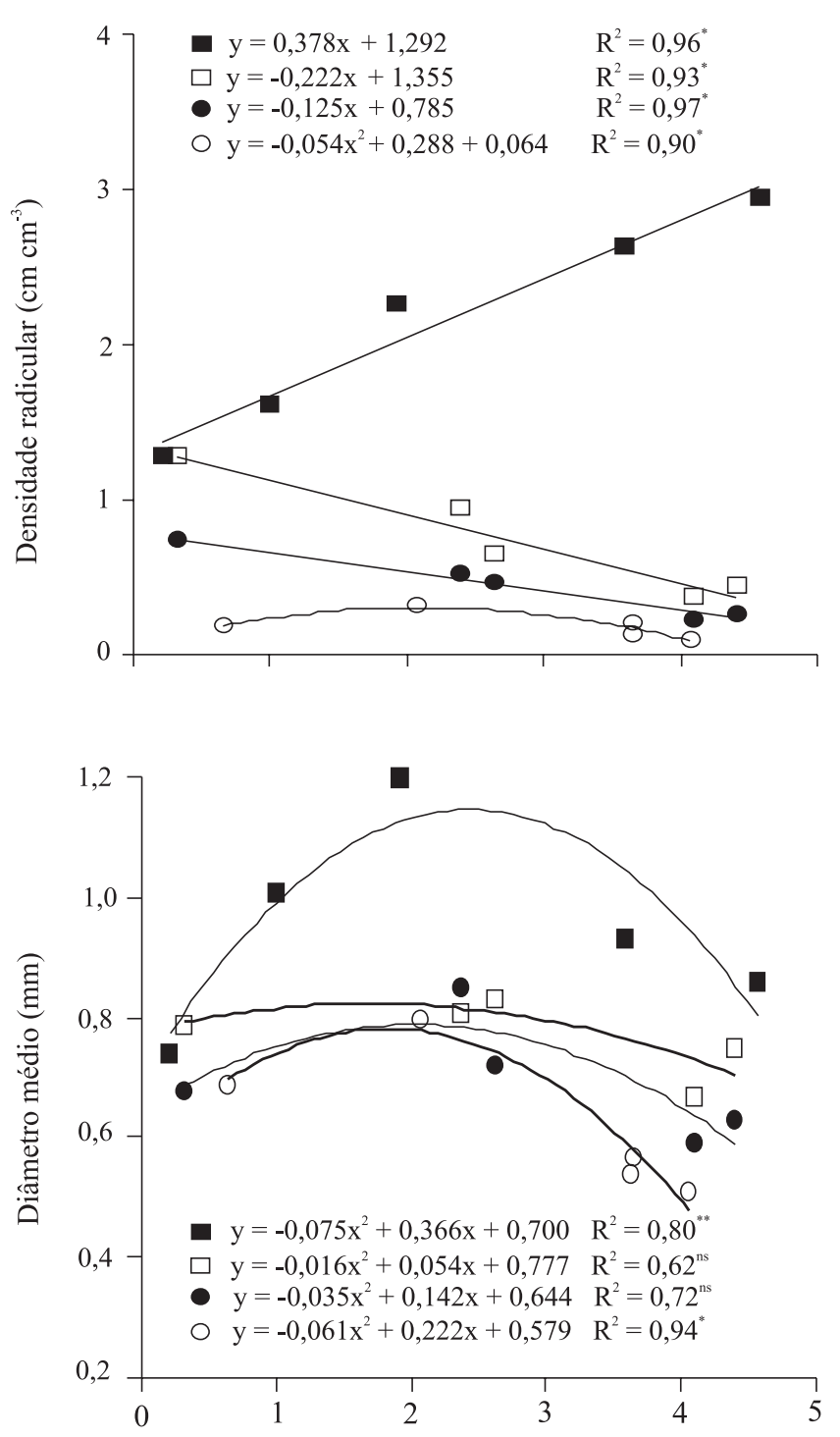

Na camada de 0,15-0,20 m, ocorreu um pequeno aumento na densidade, superfície e diâmetro das raízes com o aumento da RP, diminuindo posteriormente. Esse comportamento, conforme Queiroz-Voltan et al. (2000), ocorreu em razão do decréscimo no desenvolvimento radicular na camada de $0,05-0,15 \mathrm{~m}$ e induziu a planta a aumentar o desenvolvimento radicular nessa camada um pouco menos compactada e na superfície. No entanto, a partir do valor de RP próximo a 2,5 $\mathrm{MPa}$, o decrésci-
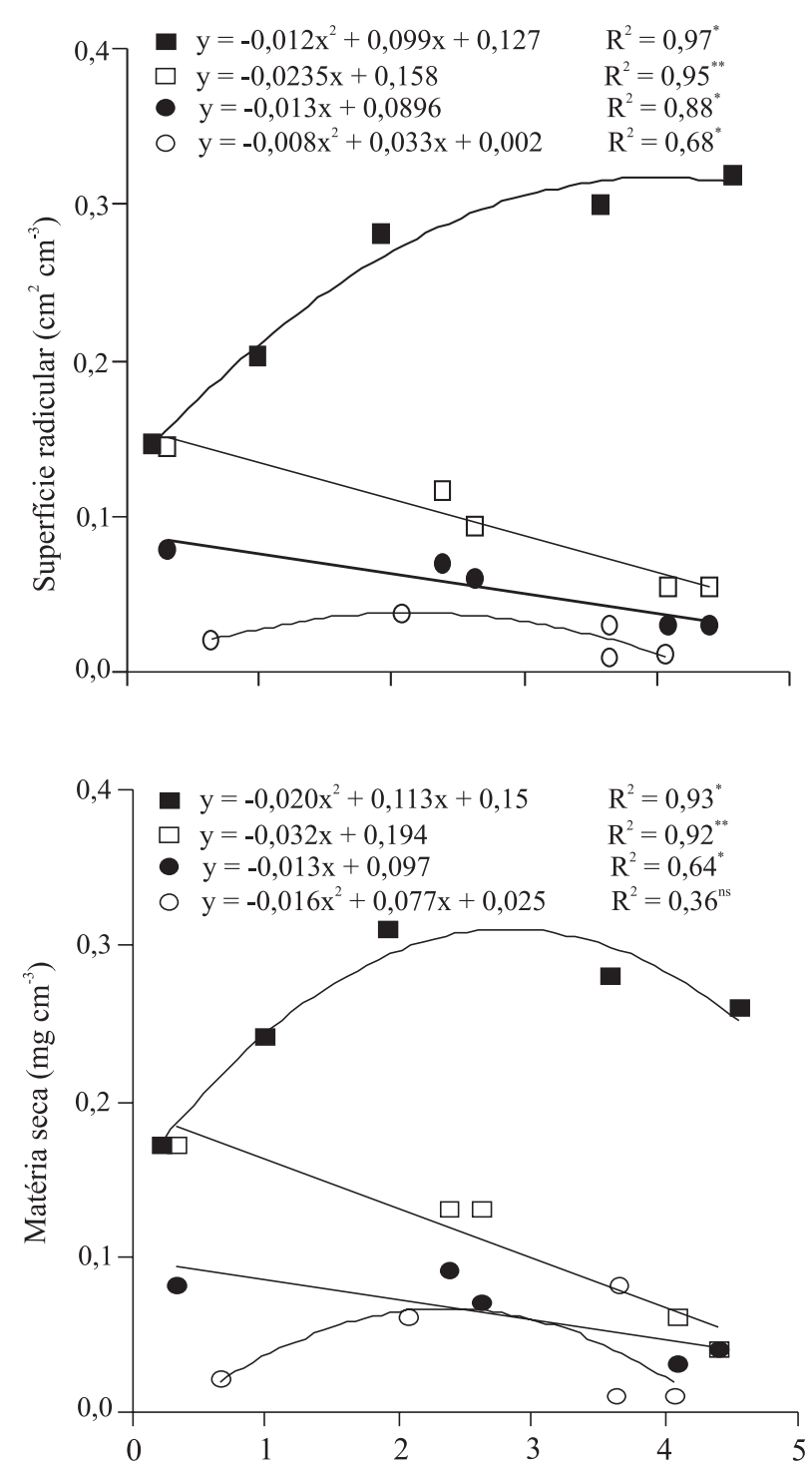

Resistência do solo à penetração $(\mathrm{MPa})$

ロ $0,0-0,05 \quad \square 0,05-0,10 \quad \bullet 0,10-0,15 \quad \bigcirc 0,15-0,20$

Figura 1. Relação entre os componentes de desenvolvimento radicular e a resistência do solo à penetração, nas camadas de

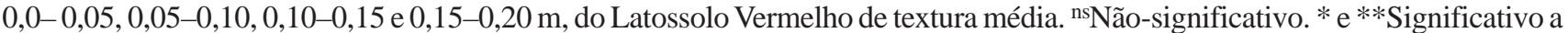
$5 \%$ e a $1 \%$ de probabilidade, respectivamente.

Pesq. agropec. bras., Brasília, v.39, n.6, p.581-588, jun. 2004 
mo do desenvolvimento radicular na camada de 0,05-0,15 m refletiu no decréscimo na camada de 0,15-0,20 m. Essa característica da planta de soja de tentar suprir o menor desenvolvimento radicular na camada compactada, aumentando o desenvolvimento radicular nas regiões superior e inferior menos compactadas, de forma a compensar os efeitos supressivos da compactação, também foi observada por Nogueira \& Manfredini (1983) na cultivar Santa Rosa e por Rosolem et al. (1994) na cultivar Primavera, em experimentos realizados em vasos.

Guimarães et al. (2002) verificaram, em vasos, que na camada superficial de solo compactada a densidade radicular e a massa de matéria seca diminuíram e a espessura das raízes do feijoeiro aumentou com o aumento da compactação, e abaixo da camada compactada de 0,20 m ocorreu aumento na densidade radicular com o aumento da compactação na camada superior.

Quanto ao diâmetro médio das raízes, não foram verificadas alterações significativas na camada compactada de 0,05-0,15 m, corroborando os estudos de Rosolem et al. (1994), em soja. Entretanto, Guimarães et al. (2002) verificaram que o diâmetro médio das raízes de feijão aumentou na camada compactada. Segundo Materechera et al. (1992), isso ocorre em decorrência da proliferação de raízes finas laterais, causada pela inibição do alongamento na região apical das raízes, e não da diminuição propriamente dita do diâmetro das raízes, conforme observada no presente trabalho na camada de $0,0-0,05 \mathrm{~m}$.

$\mathrm{Na}$ camada de $0,0-0,20 \mathrm{~m}$, verifica-se que a densidade e a superfície radicular não diferiram significativamente com o aumento da RP, e o diâmetro médio e a massa de matéria seca aumentaram até a RP de 2,07 e $1,99 \mathrm{MPa}$, respectivamente, decrescendo posteriormente (Figura 2). Esses resultados corroboram os de QueirozVoltan et al. (2000), que verificaram que a densidade de raízes de soja (cv. IAC-14) não diferiu com o aumento da compactação, e a massa de matéria seca das raízes aumentou inicialmente e posteriormente diminui com o aumento da compactação do solo, na camada de 0,0 $0,20 \mathrm{~m}$. Esse mesmo comportamento foi verificado por Moraes et al. (1995). Estes resultados indicam que o desenvolvimento de raízes em solos compactados deve ser estudado por camadas, no sentido de avaliar a sua distribuição no perfil de solo.

No maior nível de RP (média de 0,0-0,20 m) ocorreram mudanças na distribuição do sistema radicular e aumento da espessura das raízes na camada mais compactada de 0,05-0,15 m (Figura 3). Na camada de 0,0-0,05 m, o solo está visualmente menos compactado, com maior concentração de raízes finas nessa camada com o aumento da RP. Nota-se, além disso, um ligeiro espelhamento no perfil a partir da RP de 1,82 MPa, que se torna mais visível a partir da RP de 3,87 MPa. A camada compactada aumenta em profundidade no maior valor de RP de 4,25 MPa. Observa-se, ainda, o espessamento das raízes principais a partir da RP de 3,87 MPa e o seu crescimento nos planos verticais de fraqueza (rachaduras), em que ocorrem espaços livres para seu desenvolvimento. Esses resultados corroboram os de Barbieri et al. (1985), que mencionam que a compactação do solo não se apresenta de forma contínua ao longo de grandes extensões e que, em solos compactados, as raízes se desenvolvem através dos planos verticais de fraqueza.

Tão importante quanto o desenvolvimento radicular é a determinação do valor crítico de RP ao desenvolvimento radicular e sua relação com a produtividade de grãos de soja. Desta forma, foi estabelecida a equação de regressão quadrática entre a RP e a produtividade de grãos de soja, sendo obtido o valor de RP de $0,85 \mathrm{MPa}$ como valor a partir do qual a produtividade de grãos de soja decresceu (Figura 4). Este valor é inferior ao preconizado como crítico de 2,0 MPa (Tormena et al., 1998).
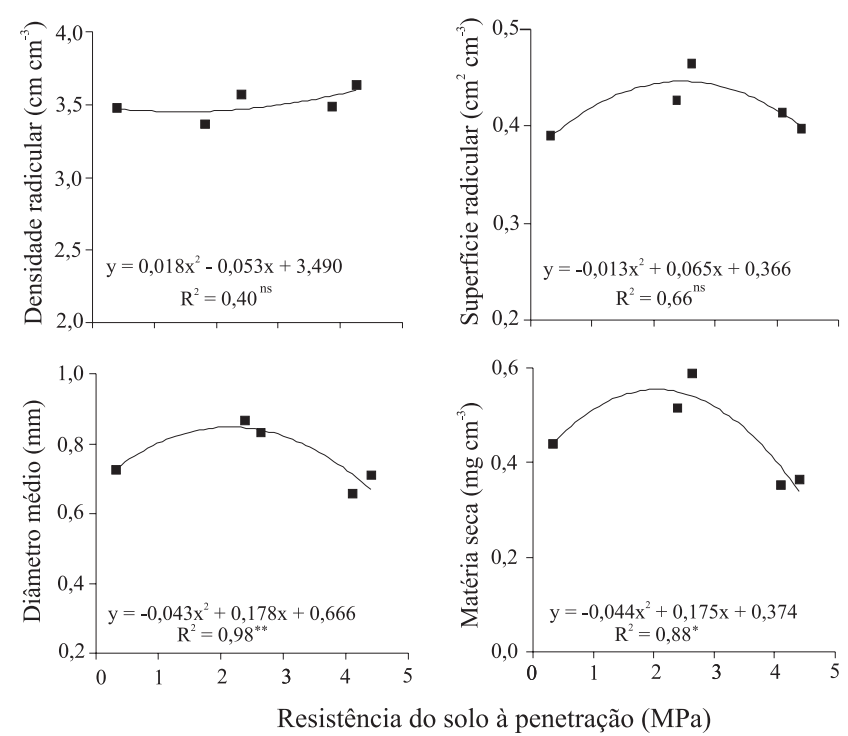

Figura 2. Relação entre os componentes de desenvolvimento radicular e a resistência do solo à penetração, na média de $0,0-0,20 \mathrm{~m}$, no Latossolo Vermelho de textura média. ns Não-significativo. $*$ e $* *$ Significativo a $5 \%$ e a $1 \%$ de probabilidade, respectivamente. 
Inserindo o valor de RP de 0,85 MPa em substituição a variável independente $(\mathrm{x})$ da equação linear da densidade radicular (Figura 1), nas camadas de 0,05-0,10 $0,10-0,15 \mathrm{~m}$, obteve-se redução de $18 \%$ na densidade radicular. Esse valor é inferior à redução de $40 \%$ do comprimento radicular considerado crítico à produtividade das culturas (Pabin et al., 1998). Isso pode ter ocorrido em razão da resposta diferenciada das culturas à compactação do solo. Por sua vez, obteve-se aumento linear no comprimento radicular na camada de
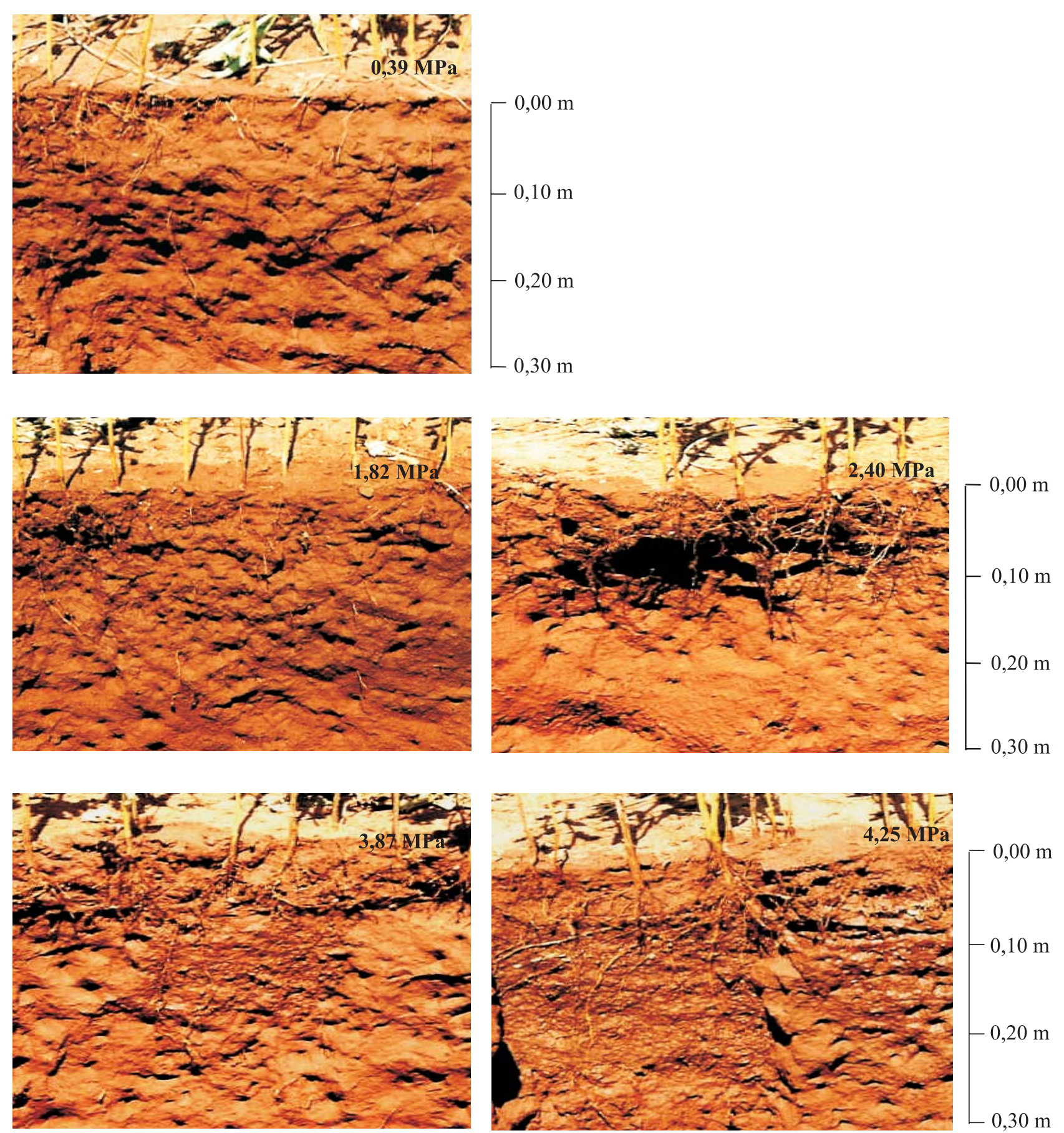

Figura 3. Perfil do desenvolvimento radicular de soja até $0,30 \mathrm{~m}$, nos diferentes níveis de resistência do solo à penetração. 
0,0-0,05 m, com menor importância no suprimento de água e nutrientes à planta, uma vez que a adubação foi realizada na profundidade em torno de $0,10 \mathrm{~m}$ e que $\mathrm{o}$ conteúdo de água na camada superficial é menor e aumenta em profundidade (Figura 5). Menor conteúdo de água na camada de $0,0-0,5 \mathrm{~m}$, em condições de menor conteúdo de água no solo, em plantio direto, também foi encontrado por Silva et al. (2000b).

Assim, em sistema de plantio direto, a alteração na distribuição de raízes em profundidade, aumentando a concentração de raízes na camada superficial de 0,0-0,05 m é fator limitante na obtenção de produtivida-

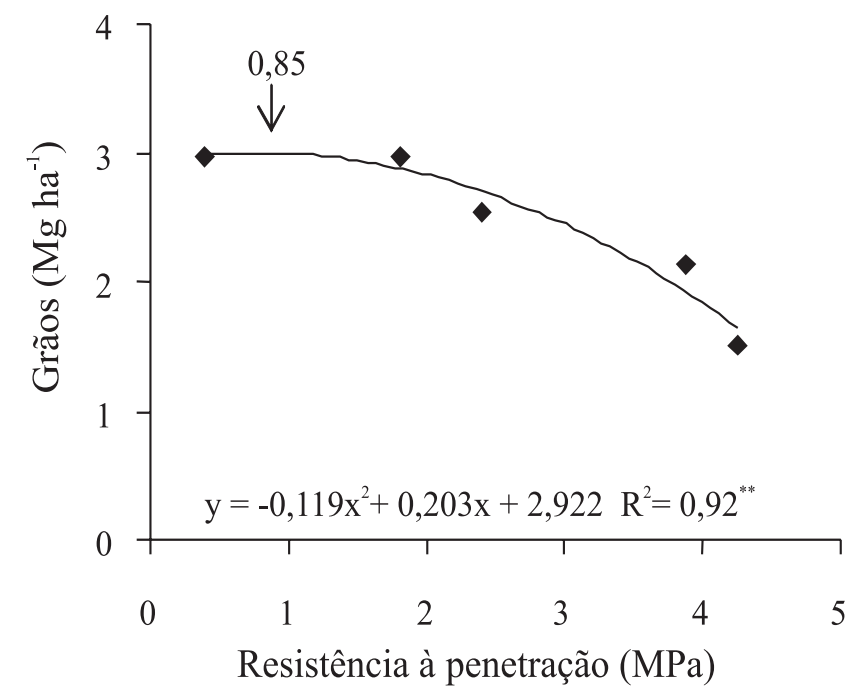

Figura 4. Relação entre a resistência à penetração e a produtividade de soja. $* *$ Significativo a $1 \%$ de probabilidade.

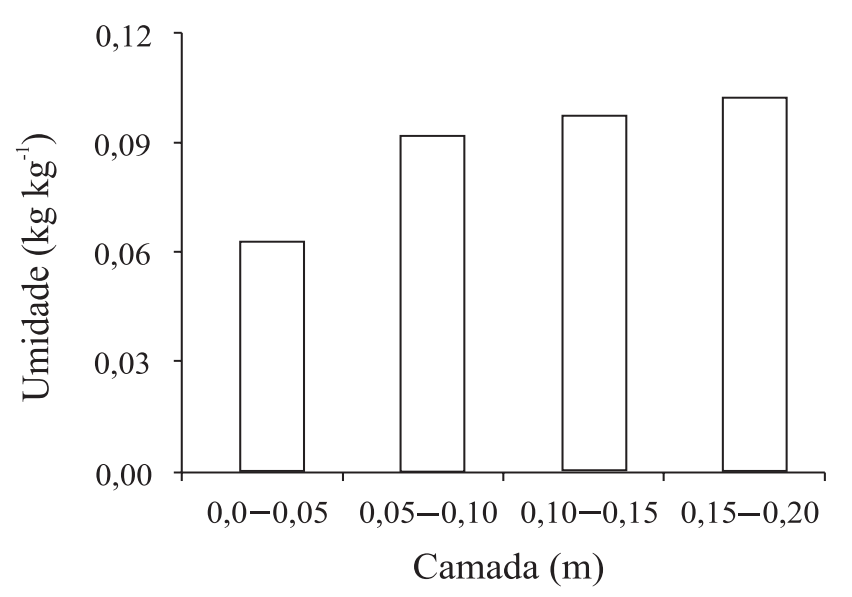

Figura 5. Umidade gravimétrica nas diferentes camadas, na condição de menor quantidade de água no solo. de adequada de soja, principalmente em condições de menor quantidade de água no solo, conforme também mencionado por Camargo \& Alleoni (1997).

\section{Conclusões}

1. O aumento da compactação do solo aumenta a densidade, a superfície e a massa de matéria seca das raízes, na camada de $0,0-0,05 \mathrm{~m}$, e causa decréscimo linear nas camadas mais compactadas de $0,05-0,10 \mathrm{e}$ $0,10-0,15 \mathrm{~m}$

2. Na média da camada de $0,0-0,20$ m não há diferença na densidade e na superfície radicular, e o diâmetro médio aumenta até a resistência à penetração de 2,07 $\mathrm{MPa}$ e a massa de matéria seca até $1,99 \mathrm{MPa}$.

3. A partir do decréscimo de $18 \%$ da densidade radicular, na resistência à penetração de $0,85 \mathrm{MPa}$, na camada de $0,05-0,15 \mathrm{~m}$, ocorre redução na produtividade da soja.

\section{Agradecimentos}

À Fapesp e ao CNPq pela concessão de bolsa ao primeiro e segundo autor, respectivamente.

\section{Referências}

AGRIANUAL 2002: anuário da agricultura brasileira. São Paulo: FNP Consultoria e Comércio, 2001. 536p.

BARBIERI, J.L.; POLI, D.M.; DONZELLE, J.L. Os Latossolos roxos e a cana-de-açúcar. Boletim Técnico Coopersucar, v.32, p.1$10,1985$.

BENGHOUGH, A.G.; MULLINS, C.E. Mechanical impedance to root growth: a review of experimental techniques and root growth root growth: a review of experimental techniques and root gro
responses. Journal of Soil Science, v.41, p.341-358, 1990.

BEUTLER, A.N.; CENTURION, J.F. Efeito do conteúdo de água e da compactação do solo na produção de soja. Pesquisa Agropecuária Brasileira, v.38, p.849-856, 2003.

BLAKE, G.R.; HARTGE, K.H. Bulk density. In: KLUTE, A. (Ed.). Methods of soil analysis: physical and mineralogical methods. 2nd ed. Madison: American Society of Agronomy, 1986. p.363-375. BORGES, E.N.; NOVAIS, R.F.; REGAZZI, A.J.; FERNANDES, B.; BARROS, N.F. Respostas de variedades de soja à compatação de camadas de solo. Revista Ceres, v.35, p.553-568, 1988.

BRASIL. Ministério da Agricultura. Comissão de Solos. Levantamento de reconhecimento dos solos do Estado de São Paulo. Rio de Janeiro, 1960. 634p.

CAMARGO, O.A.; ALLEONI, L.R.F. Compactação do solo e o desenvolvimento das plantas. Piracicaba: Esalq, 1997. 132p.

CINTRA, F.L.D.; MIELNICZUK, J. Potencial de algumas espécies vegetais para recuperação de solos com propriedades físicas 
degradadas. Revista Brasileira de Ciência do Solo, v.7, p.323327, 1983.

DANIELSON, R.E.; SUTHERLAND, P.L. Porosity. In: KLUTE, A. (Ed.). Methods of soil analysis. Madison: American Society of Agronomy, 1986. p.443-461

FEHR, W.R.; CAVINESS, C.E.; BURMOOD, D.T PENNINGTON, J.S. Stage of development description for soybeans, Glycine $\max$ (L.) Merrill. Crop Science, v.11, p.929-931, 1971.

GEE, G.W.; BAUDER, J.W. Particle-size analysis. In: KLUTE, A (Ed.). Methods of soil analysis. 2nd ed. Madison: American Society of Agronomy, 1986. pt.1, p.383-411.

GUIMAR ÃES, C.M ; STONE, L.F. MOREIRA, J.A.A. Compactação do solo na cultura do feijoeiro - II: efeito sobre o desenvolvimento radicular e da parte aérea. Revista Brasileira de Engenharia Agrícola e Ambiental, v.6, p.213-218, 2002

HAKANSSON, I.; STENBERG, M.; RYDBERG, T. Long-term experiments with different depths of mouldboard plowghing in Sweden. Soil and Tillage Research, v.46, p.209-223, 1998.

KLUTE, A. Water retention: laboratory methods. In: KLUTE, A (Ed.). Methods of soil analysis: physical and mineralogical methods. 2nd ed. Madison: American Society of Agronomy, 1986. p.635-660.

MATERECHERA, S.A.; ALSTON, A.M.; KIRBY, J.M DEXTER, A.R. Influence of root diameter on the penetration of seminal roots into a compacted subsoil. Plant and Soil, v.144, p.297-303, 1992.

MERTEN, G.H.; MIELNICZUK, J. Distribuição do sistema radicular e dos nutrientes em Latossolo Roxo sob dois sistemas de preparo do solo. Revista Brasileira de Ciência do Solo, v.15, p.369-374, 1991

MIELNICZUK, J.; CARPENEDO, V.; PEDO, F. Desenvolvimento de raízes em solos compactados. Lavoura Arrozeira, v.38, p.42-43, 1985.

MORAES, M.H.; BENEZ, S.H.; LIBARDI, P.L. Efeitos d compactação em algumas propriedades físicas do solo e seu reflexo no desenvolvimento das raízes de plantas de soja. Bragantia, v.54, p.393-403, 1995.

NOGUEIRA, S.S.S.; MANFREDINI, S. Influência da compactação do solo no desenvolvimento da soja. Pesquisa Agropecuária Brasileira, v.18, p.973-976, 1983.

PABIN, J.; LIPIEC, J.; WODEK, S. Critical soil bulk density and strength for pea seedling root growth as related to other soil factors. Soil and Tillage Research, v.19, p.131-143, 1998.

QUEIROZ-VOLTAN, R.B.; NOGUEIRA, S.S.S.; MIRANDA, M.A.C. Aspectos da estrutura da raiz e do desenvolvimento de plantas de soja em solos compactados. Pesquisa Agropecuária Brasileira, v.35, p.929-938, 2000.

RAIJ, B. van; CANTARELLA, H.; QUAGGIO, J.A.; FURLANI, A.M.C. Recomendação de adubação e calagem para o Estado de São Paulo. 2.ed. Campinas: Instituto Agronômico, 1996, 285p. (Boletim Técnico, 100)

RAIJ, B. van; QUAGGIO, J.A.; CANTARELLA, H.; FERREIRA, M.E.; LOPES, A.S.; BATAGLIA, O.C. Análise química do solo para fins de fertilidade. Campinas: Fundação Cargill, 1987. 170p. ROSOLEM C.A.; ALMEIDA, A.C.S.; SACRAMENTO, L.V.S. Sistema radicular e nutrição da soja em função da compactação do solo. Bragantia, v.53, p.259-266, 1994.

SILVA, V.R.; REINERT, D.J.; REICHERT, J.M. Densidade do solo, atributos químicos e sistema radicular do milho afetados pelo pastejo e manejo do solo. Revista Brasileira de Ciência do Solo, v.24, p.191-199, 2000a.

SILVA, V.R.; REINERT, D.J.; REICHERT, J.M. Resistência mecânica do solo à penetração influenciada pelo tráfego de uma colhedora em dois sistemas de manejo do solo. Ciência Rural, v.30, p.795-801, 2000b.

TAYLOR, H.M.; BRAR, G.S. Effect of soil compaction on root development. Soil and Tillage Research, v.19, p.111-119, 1991. TORMENA, C.A.; SILVA, A.P.; LIBARDI, P.L. Caracterização do intervalo hídrico ótimo de um Latossolo Roxo sob plantio direto. Revista Brasileira de Ciência do Solo, v.22, p.573-581, 1998.

Recebido em 17 de outubro de 2003 e aprovado em 23 de março de 2004 